\title{
Health, behaviour and growth performance of Charolais and Limousin bulls fattened on different types of flooring
}

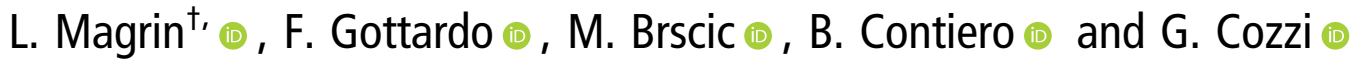 \\ Department of Animal Medicine, Production and Health, University of Padova, Viale dell'Università 16, 35020 Legnaro, Padova, Italy
}

(Received 25 October 2018; Accepted 4 April 2019; First published online 7 May 2019)

\begin{abstract}
Intensive fattening of late-maturing breeds on concrete or rubberized slatted floors is the prevalent beef production system in mainland Europe. The rationale behind this study is that specific beef breeds with different slaughter weights might have a diverse response to different flooring systems. The study aimed at assessing whether growth performance, health, behaviour and claw condition of two beef breeds, Charolais (CH) and Limousine (LIM), would be affected by their housing on concrete (CS) or rubber-covered (RCS) fully slatted floor. A total of 228 CH (116 on CS; 112 on RCS) and 115 LIM (57 on CS; 58 on RCS) were housed in four and two commercial farms, respectively, in groups of $9.0 \pm 2.1$ animals/pen with an average space allowance of $3.1 \pm 0.2 \mathrm{~m}^{2}$. Draining gaps of CS and RCS pens were $16.9 \pm 1.7 \%$ and $11.6 \pm 1.2 \%$ of the total surface, respectively. Bulls of both breeds had similar initial body weight (429.4 $\pm 31.5 \mathrm{~kg}$ for $\mathrm{CH} ; 369.6 \pm 31.7 \mathrm{~kg}$ for LIM), and they were slaughtered when they reached suitable finishing. Charolais had a higher final body weight (BW) than LIM (750.8 \pm 8.6 v. $613.7 \pm 10.9 \mathrm{~kg}$; $\mathrm{P}<0.01)$, and bulls of both breeds on RCS had higher average daily gain than on CS $(1.47 \pm 0.02 \mathrm{v} .1 .39 \pm 0.02 \mathrm{~kg} /$ day; $\mathrm{P}<0.05)$. The percentage of bulls early culled or treated for locomotor disorders were reduced by RCS only for LIM, while RCS tended to prevent the occurrence of bursitis for both breeds. During two 8-h behavioural observations, bulls on RCS performed more head butt/displacements and chases than on CS, and they reduced the frequency of abnormal lying down events. The use of $R C S$ increased mounts' frequency only in LIM, while its reduced drainage capacity impaired only the cleanliness of $\mathrm{CH}$. Postmortem hoof inspection showed longer claw dorsal wall and diagonal lengths, and sharper toe angles for CH on RCS than LIM on both floors. Results of this study point out that fully slatted floors, regardless of being rubberized or not, are not suitable for bulls finished at a final BW above $700 \mathrm{~kg}$ due to their detrimental effects on health and welfare. The use of RCS could be recommended as an alternative to CS only if bulls are slaughtered at a lower final BW (around $600 \mathrm{~kg}$ ), like in the case of LIM breed.
\end{abstract}

Keywords: finishing bulls, pen floor, concrete slats, rubber covering, welfare

\section{Implications}

Intensive fattening of late-maturing breeds is the predominant beef production system in mainland Europe. These animals are often kept on concrete slatted floor during finishing, but recently, positive effects on their welfare were reported for rubberized slatted floors. However, research on these two flooring solutions has not investigated the response of specific beef cattle breeds with different slaughter weights like Charolais and Limousine. This study suggested that fully slatted concrete floors, bare or rubberized, impaired the health and welfare of heavy bulls like Charolais. Rubberized slats could be a recommended alternative only for lower body weight bulls like Limousine.

\footnotetext{
${ }^{\dagger}$ E-mail: luisa.magrin@studenti.unipd.it
}

\section{Introduction}

The European beef cattle production accounts for almost 8 million tons of meat with France and Germany as main producing countries, followed by United Kingdom and Italy (Hocquette et al., 2018). There is a wide diversity among beef producing systems across Europe depending on cattle breeds, feeding and management solutions (European Food Safety Authority (EFSA), 2012). Dual-purpose breeds and crossbreds between dairy cows and late-maturing beef bulls are mainly reared in UK, Ireland and the Scandinavian countries. Latematuring beef cattle breeds are predominantly fattened in mainland Europe. Young stocks belonging to late-maturing beef breeds are reared in their country of origin (France, Ireland and Easter European countries) for 10 to 14 months of age, and then they are transferred to the country of destination to be finished for 6 to 7 months in specialized 
fattening units (Gallo et al., 2014). Italy imports about 1 million heads per year including young bulls and beef heifers, of which $80 \%$ from France (Cozzi, 2007). The fattening of 70\%$75 \%$ of these imported cattle is mainly carried out in specialized farms located in the Po Valley (Cozzi, 2007). As reported by Gallo et al. (2014), Charolais (CH) and Limousine (LIM) are the most imported French purebreds fattened in Italy. Charolais is generally slaughtered at a heavy BW (over $700 \mathrm{~kg}$ ), due to its well-known growth potential, feed efficiency and carcass quality (Alberti et al., 2008; Clarke et al., 2009). Limousine is slaughtered at a lower final weight (on average $590 \mathrm{~kg} \mathrm{BW}$ ) than $\mathrm{CH}$, and it is appreciated by the retail chain for its high dressing percentage and carcass fleshiness (Alberti et al., 2008).

Beef farms in Italy operate according to a rather standardized feeding programme in order to promote the maximum daily gain and to guarantee a level of rumination function. In particular, cattle are generally finished using total mixed rations based on maize silage and concentrate feedstuffs (Cozzi, 2007). During finishing, beef cattle are group housed indoors in pens with different types of floor. The fully slatted concrete floor is the most frequent flooring system used in the European fattening units because it requires low space demands and it allows an efficient manure drainage without any bedding material and additional labour for a proper litter renewal to ensure an adequate bull cleanliness (Fallon and Lenehan, 2002). However, concerns about health and welfare of beef cattle kept on fully slatted concrete floors were raised by the EFSA Panel on Animal Health and Welfare (2012). Findings by Platz et al. (2007) and Absmanner et al. (2009) showed a higher incidence of slipping events and abnormal movements for bulls kept on concrete slatted floors when standing up and lying down than for those housed on alternative flooring solutions like deep litter or different rubber surfaces. Moreover, covering concrete slats with rubber mats improved bulls' daily gain, claw health and locomotion by decreasing the occurrence of swelling in the leg joints and of white line haemorrhages in the sole (Graunke et al., 2011; Elmore et al., 2015; Keane et al., 2015). However, the scientific research on housing solutions for fattening beef cattle has never investigated the response of specific cattle breeds to different flooring systems. The aim of the present study was to assess whether growth performance, health, behaviour and claw condition of finishing bulls belonging to two beef breeds with different slaughter weight like $\mathrm{CH}$ and LIM would be affected by their housing on a concrete or on a rubber-covered slatted floor.

\section{Materials and methods}

\section{Farms, housing and management}

The study was carried out on six commercial beef cattle farms located in the Po Valley, North-eastern Italy. More details on types of floor, housing and management system of the beef cattle farm sample included in this study are described by Brscic et al. (2015b), since these farms belonged to the same
Table 1 Number of pens and of Charolais and Limousin bulls that were assigned to concrete or rubber-covered slatted floor within breed per each of the six commercial farms

\begin{tabular}{|c|c|c|c|c|c|c|}
\hline \multirow{2}{*}{$\frac{\text { Breed }}{\text { Type of floor }}$} & \multicolumn{2}{|c|}{ Charolais } & \multirow[b]{2}{*}{ Total } & \multicolumn{2}{|c|}{ Limousine } & \multirow[b]{2}{*}{ Total } \\
\hline & CS & RCS & & CS & RCS & \\
\hline \multicolumn{7}{|l|}{ Farm A } \\
\hline Number of pens & 4 & 4 & 8 & & & \\
\hline Number of bulls & 36 & 30 & 66 & & & \\
\hline \multicolumn{7}{|l|}{ Farm B } \\
\hline Number of pens & 4 & 4 & 8 & & & \\
\hline Number of bulls & 23 & 24 & 47 & & & \\
\hline \multicolumn{7}{|l|}{ Farm C } \\
\hline Number of pens & & & & 3 & 3 & 6 \\
\hline Number of bulls & & & & 36 & 36 & 72 \\
\hline \multicolumn{7}{|l|}{ Farm D } \\
\hline Number of pens & 3 & 3 & 6 & & & \\
\hline Number of bulls & 30 & 30 & 60 & & & \\
\hline \multicolumn{7}{|l|}{ Farm E } \\
\hline Number of pens & 3 & 3 & 6 & & & \\
\hline Number of bulls & 27 & 28 & 55 & & & \\
\hline \multicolumn{7}{|l|}{ Farm F } \\
\hline Number of pens & & & & 2 & 2 & 4 \\
\hline Number of bulls & & & & 21 & 22 & 43 \\
\hline \multicolumn{7}{|l|}{ Total farm sample } \\
\hline Number of pens & 14 & 14 & 28 & 5 & 5 & 10 \\
\hline Number of bulls & 116 & 112 & 228 & 57 & 58 & 115 \\
\hline
\end{tabular}

$\mathrm{CS}=$ concrete slatted floor; $\mathrm{RCS}=$ rubber covered slatted floor.

beef producers' association that was in charge of cattle feeding and health management.

In each farm, half of the experimental pens had a fully slatted concrete floor (CS) with draining gaps of $16.9 \pm 1.7$ (SD) $\%$ of the total surface. In the second half of the experimental pens, concrete slats were covered with 30-mm thick of synthetic rubber (RCS) (Riverstick Industries Ltd, Cork, Ireland), designed to match the gap profile of the slats underneath and to allow the drainage of the manure with draining gaps of $11.6 \pm 1.2 \%$ of the total surface.

A total of 343 finishing beef bulls ( $228 \mathrm{CH}$ and $115 \mathrm{LIM}$ ) were included in the study, and detailed numbers of pens and bulls considered per each farm according to type of floor and breed are reported in Table 1. In all farms, bulls were housed in groups of $9.0 \pm 2.1$ animals/pen, balanced according to their initial BW $(423.5 \pm 49.1$ and $367.4 \pm 17.8 \mathrm{~kg} \mathrm{BW}$ for $\mathrm{CH}$ and LIM, respectively), and the average individual space allowance was $3.1 \pm 0.2 \mathrm{~m}^{2}$. All pens were equipped with two pressure water bowls for the provision of drinking water. In all farms, bulls were fed a finishing total mixed ratio based on maize silage delivered ad libitum once a day in the morning (between 0900 and $1000 \mathrm{~h}$ ). Dietary samples were collected throughout the study and analysed for DM and CP according to the methods of the Association of Official Analytical Chemists (AOAC, 2000). Analysis of NDF of the same samples was carried out according to Van Soest et al. (1991), while starch content was determined by liquid chromatography (AOAC, 2000). Diets offered to CH bulls had 
an average DM content of $58.6 \pm 6.9 \%$, a CP content of $13.5 \pm 1.0 \% \mathrm{DM}$, a starch content of $31.5 \pm 4.4 \% \mathrm{DM}$ and an NDF content of $31.4 \pm 4.4 \%$ DM. Diets provided to LIM bulls had an average DM content of $58.5 \pm 5.4 \%$, a CP content of $14.0 \pm 1.2 \% \mathrm{DM}$, a starch content of $32.9 \pm 2.4 \%$ DM and an NDF content of $29.6 \pm 3.7 \%$ DM.

\section{Growth performance, carcass weights and health status}

All bulls housed in each pen were weighed as a group in a group livestock scale to reduce stress and risk of injuries at the beginning and at the end of the finishing period. Initial and final BW were used to calculate pen average daily gain (ADG). A beef cattle market expert set the end of the finishing period according to the achievement of a suitable finishing of all bulls in each pen. Bull carcass weights were gathered from the slaughterhouse personnel. The same veterinarian belonging to the producers' association was in charge of bulls' health in all farms. Individual health status of the animals was daily checked throughout the finishing period. Visually sick/lame animals were temporarily removed from the fattening pens to a sick bay to receive pharmaceutical treatment until healing. The number of bulls that were treated for respiratory and locomotor disorders was recorded as well as the number of bulls that were early culled due to fatal or traumatic events or lameness. A trained fixed veterinarian performed an individual bull's health check the last month of finishing in all farms. Each bull was visually inspected from the feeding alley, and the occurrence of front and hind leg problems such as bursitis (swelling), alopecia and lesion/wound was recorded as binary variables (presence/absence) according to the Welfare Quality ${ }^{\circledR}$ Assessment protocol for cattle (Welfare Quality ${ }^{\circledR}, 2009$ ). The individual cleanliness of the animals, as a sign of comfort around resting, was assessed according to same protocol for cattle.

\section{Behaviour}

In all farms, two 8-h behavioural observation sessions were carried out during the study by a fixed team of four trained assessors. The first observation session was carried out 1 month after the housing of the bulls in the experimental pens, whereas the second one was carried out 2 weeks before the expected slaughter day. Two assessors per each floor type were in charge of the behavioural observations starting right after feed distribution: one assessor recorded the continuous behaviours and the other the events. Position and type of data recorded by each assessor changed in a rotational manner every $2 \mathrm{~h}$ to reduce the bias due to the observer effect. The number of bulls standing/lying and eating, ruminating, inactive, resting or involved in other activities in each pen was recorded using the scan-sampling technique with a 5-min interval between two consecutive scans (96 scans/pen/observation session) (Martin and Bateson, 2007). Mounting, chasing, head butt/displacement, slipping, unsuccessful attempts to lie down and abnormal lying down were recorded as events whenever they occurred ( 1 = occurrence) at pen level using the behaviour-sampling technique (Martin and Bateson, 2007). The ethogram is described in detail by Brscic et al. (2015b). A fixed fifth assessor was in charge of measuring durations of the lying-down sequences using a stopwatch in all farms (Welfare Quality ${ }^{\circledR}$, 2009).

\section{Postmortem claw measurements}

All the animals were slaughtered in the same abattoir owned and managed by the producers' association. Front and hind feet of a minimum of nine bulls/floor type/farm were randomly chosen and inspected postmortem by the same trained veterinarian. Similar to Platz et al. (2007), dorsal wall length, diagonal length and toe angle of lateral claws on the left feet and of medial claws on the right feet were measured. A total of 121 bulls were inspected at the slaughterhouse recording front and hind claw measurements $(n=480$ claw measurements).

\section{Statistical analysis}

Pen was the experimental unit for bulls' growth performance, continuous behavioural data and events. The single animal was the statistical unit for data regarding carcass weights, time to lying down, clinical traits, cleanliness and claw dimensions. Initial and final BW, ADG, days of fattening and carcass weight were analysed using a mixed model that considered the fixed effect of breed, type of floor and their interaction, with farm nested within breed as random effect and the Bonferroni adjustment option. Continuous behavioural data gathered using the scan-sampling technique were expressed as percentage of bulls performing each behavioural activity per scan per pen, while events were expressed as number of events performed per bull during the observation session at the pen level. These data were processed using a mixed model that considered breed, observation session, type of floor and breed $\times$ type of floor interaction as fixed effects, considering farm as a random effect, the observation session as repeated option (Proc Mixed of SAS 9.3; SAS Institute Inc., Cary, NC, USA) and the Bonferroni adjustment option. Intraclass correlation coefficients (ICC) were calculated for behavioural data gathered during the two observation sessions to assess agreement between observers a posteriori both for breed and type of floor effects using MedCalc Statistical Software (MedCalc Software 17.6 bvba, Ostend, Belgium). Statistical analyses of variables expressed as proportions regarding treated and early culled bulls were performed using $\chi^{2}$ tests (with the Marascuilo procedure) to verify their association with the type of floor within breed. Variables gathered as binary regarding bulls' cleanliness and health were expressed as percentages of bulls. When the prevalence resulted $\geq 1 \%$, they were tested for association with the type of floor within breed using the one-way logistic regression analysis (Proc Logistic of SAS 9.3; SAS Institute Inc., Cary, NC, USA), and the odds ratio (OR) and 95\% confidence intervals $(\mathrm{Cl})$ were calculated using RCS as term of comparison. Claw measurements were analysed using a mixed model (Proc Mixed of SAS 9.3; SAS Institute Inc., Cary, NC, USA) that considered the effect of breed, type 
Magrin, Gottardo, Brscic, Contiero and Cozzi

Table 2 Growth performance and carcass weights of Charolais and Limousin bulls housed on different types of floor during the finishing period (least squares means) in six commercial farms

\begin{tabular}{|c|c|c|c|c|c|c|c|c|}
\hline \multirow{2}{*}{$\frac{\text { Breed (B) }}{\text { Type of floor (TF) }}$} & \multicolumn{2}{|c|}{ Charolais } & \multicolumn{2}{|c|}{ Limousine } & \multirow[b]{2}{*}{ SEM } & \multicolumn{3}{|c|}{$P$-value } \\
\hline & CS & RCS & CS & RCS & & B & TF & $\mathrm{B} \times \mathrm{TP}$ \\
\hline Number of bulls & 116 & 112 & 57 & 58 & & & & \\
\hline \multicolumn{9}{|l|}{ Live weight $(\mathrm{kg})$} \\
\hline Initial & 427.2 & 431.7 & 370.5 & 368.7 & 32.2 & 0.313 & 0.877 & 0.719 \\
\hline Final & 739.6 & 762.0 & 606.4 & 621.1 & 11.2 & 0.002 & 0.029 & 0.635 \\
\hline Days of fattening & 222.5 & 221.0 & 179.2 & 180.4 & 21.0 & 0.252 & 0.969 & 0.723 \\
\hline Average daily gain (kg/day) & 1.46 & 1.53 & 1.32 & 1.40 & 0.03 & 0.068 & 0.022 & 0.841 \\
\hline Carcass weight $(\mathrm{kg})$ & 440.4 & 451.1 & 378.2 & 392.8 & 7.93 & 0.011 & 0.001 & 0.612 \\
\hline
\end{tabular}

$\mathrm{CS}=$ concrete slatted floor; $\mathrm{RCS}=$ rubber covered slatted floor; $\mathrm{SEM}=$ standard error of mean.

Table 3 Effect of the type of floor on the percentage of treated (for locomotor or respiratory disorders) and early culled Charolais and Limousin bulls during the finishing period in six commercial farms

\begin{tabular}{|c|c|c|c|c|c|c|}
\hline \multirow{2}{*}{$\frac{\text { Breed }}{\text { Type of floor }}$} & \multicolumn{2}{|c|}{ Charolais } & \multirow[b]{2}{*}{$P$-value } & \multicolumn{2}{|c|}{ Limousine } & \multirow[b]{2}{*}{$P$-value } \\
\hline & CS & RCS & & CS & RCS & \\
\hline \multicolumn{7}{|l|}{ Treated bulls (\% of bulls) } \\
\hline For respiratory disorders & 4.31 & 4.46 & 0.974 & 10.5 & 8.62 & 0.687 \\
\hline For locomotor disorders & 4.31 & 1.79 & 0.233 & 15.8 & 1.72 & 0.014 \\
\hline Early culled (\% of bulls) & 6.03 & 3.57 & 0.378 & 3.51 & 0.00 & 0.090 \\
\hline
\end{tabular}

$\mathrm{CS}=$ concrete slatted floor; $\mathrm{RCS}=$ rubber covered slatted floor.

of floor and their interaction as fixed and of farm as random effects, with the Bonferroni adjustment option. Regarding the normality and homoscedasticity of the errors, the hypotheses of the linear model were graphically assessed by visual inspection of the studentized residuals, and all variables met the model assumptions.

\section{Results}

Regardless of breed and type of floor, bulls had similar initial BW at the onset of the finishing period (Table 2). Final BW of bulls differed according to breed and type of floor (Table 2). In particular, $\mathrm{CH}$ bulls were heavier at the end of the fattening period compared to LIM bulls $(750.8 \pm 8.6$ v. $613.7 \pm 10.9$ $\mathrm{kg} ; P<0.01$ ), and bulls kept in RCS pens had higher BW than those kept in CS pens $(691.5 \pm 8.0$ v. $673.0 \pm 8.0 \mathrm{~kg} ; P<$ $0.05)$. There were no breed and type of floor effects on the duration of the fattening. Average daily gain tended to be higher for $\mathrm{CH}$ than LIM bulls $(1.50 \pm 0.03$ v. $1.36 \pm$ $0.03 \mathrm{~kg} /$ day; $P=0.068$ ), and it was significantly higher for bulls housed on RCS than for those on CS floor (1.47 \pm 0.02 v. $1.39 \pm 0.02 \mathrm{~kg} /$ day; $P<0.05)$. Carcass weights of $\mathrm{CH}$ bulls were heavier than those of LIM bulls (445.7 \pm 6.7 v. $385.5 \pm 8.2 \mathrm{~kg} ; P<0.5)$, and it increased for bulls housed on RCS than for those on CS floor $(421.9 \pm 5.6 \mathrm{v}$. $409.3 \pm 5.7 \mathrm{~kg} ; P<0.01)$. No breed $\times$ type of floor interactions were observed for bulls' growth and slaughter performance (Table 2). Type of floor did not affect the percentage of $\mathrm{CH}$ bulls treated for respiratory and locomotor disorders, nor the percentage of $\mathrm{CH}$ bulls that were early culled due to traumatic events or lameness (Table 3). In case of LIM, RCS floor significantly reduced the percentage of bulls treated for locomotor disorders and tended to lower the number of early culled bulls (Table 3). Odds ratio values indicated that RCS floor tended to be a preventive measure against the occurrence of bursitis for both breeds (Table 4). The type of floor did not affect the prevalence of $\mathrm{CH}$ bulls showing lesion/ wound or alopecia. Lesion/wounds were detected in $1.2 \%$ of LIM bulls on RCS floor and in none on CS floor. No signs of alopecia were found in LIM bulls housed on both flooring systems. The risk to be dirty was higher for $\mathrm{CH}$ bulls kept in RCS pens than for those kept in CS pens, but it did not differ for LIM bulls housed on the same floors (Table 4).

During the two observation sessions the agreement between observers was good both for breed and for the type of floor, since the ICC calculated on the percentages of all behavioural variables were $\geq 0.70$. Observation of continuous behaviour showed a similar proportion of $\mathrm{CH}$ and LIM bulls standing, and there were no type of floor and observation session effects on standing behaviour (Table 5). Sternal recumbency with all four limbs folded underneath the body was the most frequent lying postures of all bulls, and its recorded frequency did not vary between types of floor, nor between breeds. It was affected by the observation session, being more frequently at the beginning of the fattening than at the end of it $(38.5 \pm 2.4$ v. $30.3 \pm 2.4 \% ; P<0.05)$. The proportion of bulls lying with one front limb extended was higher for $\mathrm{CH}$ than LIM bulls $(18.2 \pm 0.9$ v. $13.0 \pm$ $1.5 \% ; P<0.05)$, and for bulls housed on CS than for those housed on RCS floor $(20.0 \pm 1.2$ v. $11.1 \pm 1.3 \% ; P<0.01)$. Breed and type of floor had no effect on the proportion of bulls lying with two limbs extended or with lateral recumbency, or resting. Among them, only the proportion of bulls with lateral recumbency varied for the observation session effect, being more frequently at the end than at the beginning of the fattening $(3.77 \pm 0.9$ v. $7.09 \pm 0.9 \% ; P<$ 0.05). Both breeds performed eating and ruminating activities with a similar frequency, and the type of floor did not affect them (Table 5). Bulls performed rumination 
Beef bulls on concrete or rubberized slatted floor

Table 4 Effect of the type of floor on the prevalence (\%) of Charolais and Limousin bulls with bursitis, lesion/wound, alopecia and dirty coat at the in vivo health check carried out 1 month before the end of the finishing period in six commercial farms

\begin{tabular}{|c|c|c|c|c|c|c|c|c|}
\hline \multirow{2}{*}{$\frac{\text { Breed }}{\text { Type of floor }}$} & \multicolumn{2}{|c|}{ Charolais } & \multirow[b]{2}{*}{ OR $(95 \% \mathrm{Cl})^{1}$} & \multirow[b]{2}{*}{$P$-value } & \multicolumn{2}{|c|}{ Limousine } & \multirow[b]{2}{*}{ OR $(95 \% \mathrm{Cl})^{1}$} & \multirow[b]{2}{*}{$P$-value } \\
\hline & CS & RCS & & & CS & RCS & & \\
\hline Bursitis & 22.5 & 13.5 & $1.87(0.90$ to 3.88$)$ & 0.092 & 34.5 & 19.0 & $2.26(0.95$ to 5.33$)$ & 0.064 \\
\hline Lesion/wound & 7.8 & 2.9 & $2.87(0.74$ to 11.1$)$ & 0.128 & 0.0 & 1.2 & - & - \\
\hline Alopecia & 9.8 & 8.6 & $1.15(0.45$ to 2.95$)$ & 0.776 & 0.0 & 0.0 & - & - \\
\hline Dirtiness & 43.5 & 67.6 & $0.37(0.25$ to 0.55$)$ & $<0.001$ & 37.0 & 44.8 & $0.724(0.42$ to 1.24$)$ & 0.237 \\
\hline
\end{tabular}

$\mathrm{CS}=$ concrete slatted floor; $\mathrm{RCS}=$ rubber covered slatted floor.

${ }^{1}$ Estimated odd ratios (OR) and $95 \%$ confidence intervals (CI) using RCS within breed as term of comparison.

Table 5 Effect of the type of floor on behaviours of Charolais and Limousin bulls recorded during two 8-h observation sessions starting right after feed delivery carried out 1 month after the beginning and 2 weeks before the expected end of their finishing period in six commercial farms (least squares means)

\begin{tabular}{|c|c|c|c|c|c|c|c|c|}
\hline \multirow{2}{*}{$\frac{\text { Breed (B) }}{\text { Type of floor (TF) }}$} & \multicolumn{2}{|c|}{ Charolais } & \multicolumn{2}{|c|}{ Limousine } & \multirow[b]{2}{*}{ SEM } & \multicolumn{3}{|c|}{$P$-value } \\
\hline & CS & RCS & CS & RCS & & B & TF & $\mathrm{B} \times \mathrm{TF}$ \\
\hline \multicolumn{9}{|l|}{ Continuous behaviour ( $\%$ of bulls) } \\
\hline $\begin{array}{l}\text { Standing } \\
\text { Lying posture }\end{array}$ & 53.1 & 55.5 & 53.2 & 55.6 & 5.25 & 0.989 & 0.496 & 0.987 \\
\hline Sternal recumbency & 32.6 & 34.3 & 34.1 & 36.5 & 3.34 & 0.682 & 0.444 & 0.896 \\
\hline Sternal with one front limb extended & 22.2 & 14.1 & 17.8 & 8.19 & 1.70 & 0.046 & 0.006 & 0.691 \\
\hline Sternal with two front limbs extended & 1.36 & 1.24 & 0.71 & 0.75 & 0.38 & 0.157 & 0.939 & 0.872 \\
\hline Lateral recumbency & 5.38 & 5.40 & 6.80 & 4.14 & 1.31 & 0.966 & 0.138 & 0.134 \\
\hline Resting & 35.6 & 31.6 & 34.1 & 31.9 & 3.93 & 0.914 & 0.269 & 0.720 \\
\hline Eating & 13.5 & 17.7 & 18.2 & 17.5 & 2.75 & 0.573 & 0.356 & 0.207 \\
\hline \multicolumn{9}{|l|}{ Ruminating } \\
\hline While standing & 5.14 & 4.62 & 3.97 & 3.44 & 0.76 & 0.308 & 0.300 & 0.993 \\
\hline While lying & 11.3 & 12.9 & 12.8 & 12.5 & 1.96 & 0.854 & 0.557 & 0.413 \\
\hline
\end{tabular}

$\mathrm{CS}=$ concrete slatted floor; $\mathrm{RCS}=$ rubber covered slatted floor; $\mathrm{SEM}=$ standard error of mean.

predominantly during lying, and more frequently at the beginning of the fattening $(15.9 \pm 1.4$ v. $8.79 \pm 1.4 \%$ for the first and second observation, respectively; $P<0.01$ ). Breed $\times$ type of floor interactions for the occurrence of events are shown in Figure 1. A significant type of floor effect $(P<$ 0.05 ) was observed for head butt/displacement and chasing events that were recorded with a higher frequency in bulls of both breeds on RCS compared to CS floor $(0.89 \pm 0.10$ v. 0.55 \pm 0.10 for head butts/displacements; $0.08 \pm 0.01$ v. $0.03 \pm$ 0.01 for chases). The use of RCS floor increased the frequency of mounting events only in LIM bulls while slipping events did not differ according to both breed and type of floor. Regardless of breed, bulls kept in CS pens had a higher frequency of unsuccessful lie-down attempts $(0.08 \pm 0.01 \mathrm{v}$. $0.03 \pm 0.01 ; P<0.05)$ and of abnormal lie-down events $(0.02 \pm 0.004$ v. $0.01 \pm 0.004 ; P<0.01)$ than bulls in RCS pens. Slipping events and unsuccessful lie-down attempts occurred more frequently for bulls at the beginning than at the end of the fattening $(0.35 \pm 0.06 \mathrm{v} .0 .21 \pm 0.06$ for slips; $0.08 \pm 0.01$ v. $0.04 \pm 0.01$ for attempts to lie down; $P<0.05)$. A significant breed $\times$ type of floor interaction (Figure 2) was recorded for the time required by bulls to lie down $(P<0.05)$. In particular, lying-down duration was longer for LIM bulls housed on CS floor, lower for $\mathrm{CH}$ and LIM bulls on RCS floor and intermediate for $\mathrm{CH}$ bulls on CS floor.

Charolais bulls housed on RCS floor had longer dorsal wall lengths of both front and hind claws compared to $\mathrm{CH}$ bulls on CS floor and LIM bulls on both floors (Table 6). Diagonal lengths of both front and hind claws were longer for $\mathrm{CH}$ bulls housed on RCS floor, shorter for LIM bulls housed on CS floor and intermediate for the other bulls. Toe angles measured on both front and hind claws were greater for LIM bulls kept in RCS pens, intermediate for LIM and CH bulls kept in CS pens and lower for $\mathrm{CH}$ bulls kept in RCS pens (Table 6).

\section{Discussion}

Supporting the previous findings of Alberti et al. (2008), the great growth potential of $\mathrm{CH}$ bulls resulted in a heavier slaughter weight than LIM bulls. Bulls of both breeds showed improved growth performance on RCS floor, and this positive effect of rubberized concrete floor coverings was also confirmed by Cozzi et al. (2013). In literature, CH has been considered a sensitive breed to lameness, especially after a long-term housing on CS floor (Brscic et al., 2015a). In the 

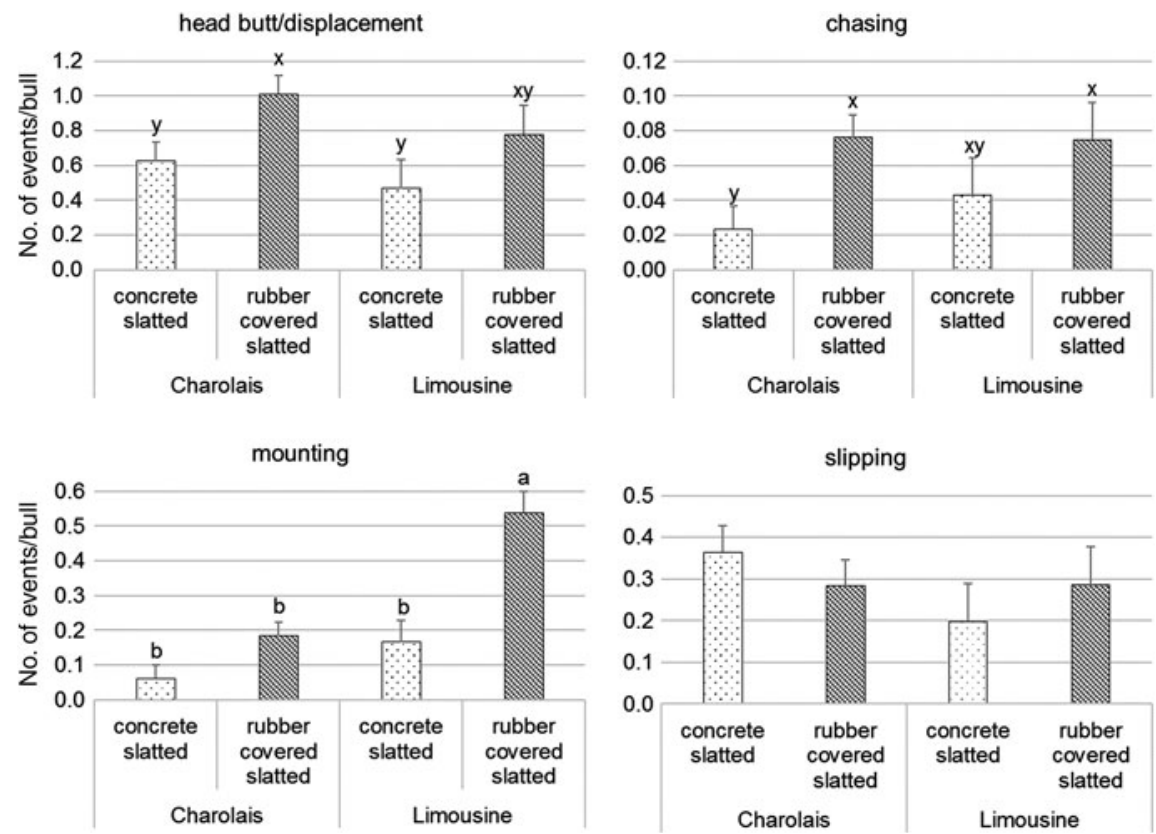

Figure 1 Effect of the type of floor $x$ breed interaction on the number of events performed by bulls during the 8-h observation sessions (least squares means) in six commercial farms. Different letters indicate significant differences within a given event $(a, b: P<0.05 ; x, y: P<0.10)$.
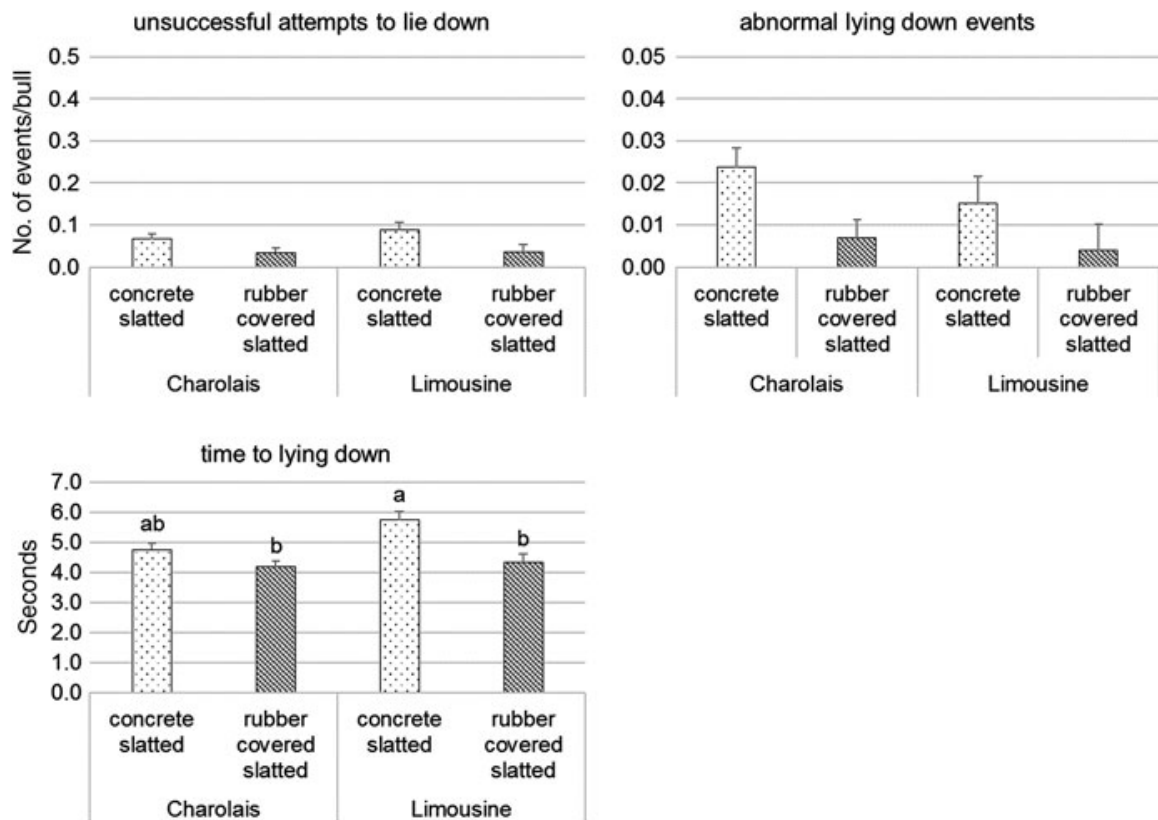

Figure 2 Effect of the type of floor $\times$ breed interaction on the lying-down behaviour of bulls during the 8-h observation sessions (least squares means) in six commercial farms. Different letters indicate significant differences within a given lying-down behaviour for $P<0.05$.

present study, the rubber covering of concrete slats did not reduce the number of $\mathrm{CH}$ bulls that were early culled, but it tended only to lower the occurrence of bursitis. Results of our study showed that also LIM bulls suffered of the housing on hard surface like CS floor, increasing the occurrence of bursitis and the prevalence of animals treated for locomotor disorders. In beef cattle, leg lesions have been associated to the exposure of the limbs to hard and abrasive surfaces (Platz et al., 2007; Schulze Westerath et al., 2007), and the increased prevalence of bursitis observed in our study for both breeds on CS floor fully supports this finding. The occurrence of further integumental alterations such as lesion/wounds and hairless patches observed only in $\mathrm{CH}$ bulls might instead arise from additional stressors to their joints due to the heavier body weight which narrowed space allowance over time (Graunke et al., 2011; Wechsler, 2011; Elmore et al., 2015). Support to this assumption comes from Brscic et al. (2015a) who reported a higher occurrence of hairless patches and lesions/swellings in heavy bulls at the end of their finishing period. Absmanner et al. (2009) considered the extension 
Beef bulls on concrete or rubberized slatted floor

Table 6 Effect of the type of floor on front and hind claw measurements of Charolais and Limousin bulls from six commercial farms at postmortem inspection (least squares means)

\begin{tabular}{|c|c|c|c|c|c|c|c|c|}
\hline \multirow{2}{*}{$\frac{\text { Breed (B) }}{\text { Type of floor (TF) }}$} & \multicolumn{2}{|c|}{ Charolais } & \multicolumn{2}{|c|}{ Limousine } & \multirow[b]{2}{*}{ SEM } & \multicolumn{3}{|c|}{$P$-value } \\
\hline & CS & RCS & CS & RCS & & B & TF & $\mathrm{B} \times \mathrm{TF}$ \\
\hline Number of bulls & 37 & 36 & 24 & 24 & & & & \\
\hline \multicolumn{9}{|l|}{ Front claws } \\
\hline Dorsal wall length $(\mathrm{cm})$ & $7.58^{c}$ & $8.78^{a}$ & $7.68^{c}$ & $8.27^{\mathrm{b}}$ & 0.11 & 0.076 & $<0.001$ & 0.009 \\
\hline Diagonal length $(\mathrm{cm})$ & $17.6^{\mathrm{b}}$ & $19.3^{a}$ & $16.5^{c}$ & $17.2^{\mathrm{b}}$ & 0.16 & $<0.001$ & $<0.001$ & 0.001 \\
\hline Toe angle $\left(^{\circ}\right)$ & $59.6^{\mathrm{ab}}$ & $50.0^{c}$ & $55.0^{\mathrm{b}}$ & $60.9^{a}$ & 1.46 & 0.059 & 0.164 & $<0.001$ \\
\hline \multicolumn{9}{|l|}{ Hind claws } \\
\hline Dorsal wall length $(\mathrm{cm})$ & $7.59^{b}$ & $8.86^{a}$ & $7.55^{b}$ & $8.01^{b}$ & 0.13 & 0.001 & $<0.001$ & 0.002 \\
\hline Diagonal length $(\mathrm{cm})$ & $16.0^{\mathrm{b}}$ & $17.4^{\mathrm{a}}$ & $14.8^{c}$ & $15.4^{\mathrm{bc}}$ & 0.17 & $<0.001$ & $<0.001$ & 0.018 \\
\hline Toe angle $\left({ }^{\circ}\right)$ & $58.7^{\mathrm{ab}}$ & $49.5^{c}$ & $54.5^{b}$ & $60.4^{\mathrm{a}}$ & 1.20 & 0.012 & 0.135 & $<0.001$ \\
\hline
\end{tabular}

$\mathrm{CS}=$ concrete slatted floor; RCS = rubber covered slatted floor; $\mathrm{SEM}=$ standard error of mean

$a, b, c$ values within a row with different superscripts differ for the reported $P$-value.

of one front limb as a possible strategy to get some relief in the leg joints during lying. The reduced frequency of this posture observed in both breeds when kept in RCS pens could be a sign of their better comfort. The additional stress coming from the heavy BW of $\mathrm{CH}$ bulls might explain the significant breed effect observed for this lying posture. However, the reduced lying comfort was observed for all bulls as the fattening cycle progressed since the percentage of bulls in sternal recumbency decreased and that of those in lateral recumbency increased. Several authors (Platz et al., 2007; Graunke et al., 2011) hypothesized that the slippery surface of the concrete slatted floor was an explanation for the inhibition of social interactions involving powerful movements in beef cattle. Rubber covering for concrete floors has been shown to improve bulls' confidence to exhibit natural behaviours and forceful social interactions such as head butt/displacements, chases and mounts, although it did not achieve the welfare potential of straw bedding (Lowe et al., 2001; Gygax et al., 2007a; Absmanner et al., 2009). In this study, the number of all these pen-mates' interactions increased when LIM bulls were housed on the RCS floors. Charolais bulls showed a similar trend, except for the mounting events that did not change according to the type of floor. Mounting is a sexual behaviour shown by fattening bulls to establish the inner hierarchy among pen-mates (Phillips, 1993). The breed $\times$ type of floor interaction observed for this behaviour might have several explanations. When housed on a floor like RCS that provides a satisfactory hoof grip, the more excitable temperament of LIM breed, previously recorded by Phocas et al. (2006) and Hoppe et al. (2010), could have encouraged mounting events in an attempt to stabilize hierarchy among pen-mates. However, since it was demonstrated that finishing bulls change their behaviour in relation to space allowance (Gupta et al., 2007; Gygax et al., 2007b), we cannot exclude that the lower space allowance for $\mathrm{CH}$ bulls caused by their heavy BW and larger body frame might have inhibited the performing of extreme and more powerful social interaction as mounts, head butts/ displacements or chases, especially when housing on hard surfaces. Considering that the observers in charge of the behavioural assessments were not blind to treatments, we could not fully exclude an additional observer effect although the study was implemented according to ethical conduct in research. In addition, in this study, bulls exercised more caution on movements as the fattening cycle progressed, and this finding may be supported by the decreasing number of slips and unsuccessful attempts to lie down recorded in the final part of fattening. However, it has been demonstrated that fattening bulls perform transitions more cautiously when kept on hard and slippery floors like CS because they are painful and potentially traumatic (Platz et al., 2007). Consistent with Gygax et al. (2007a), in our study, all bulls housed on RCS floor had a lower frequency either because of unsuccessful attempts to lie down or because of abnormal lying-down events, both well-known indicators of housing discomfort. The increased confidence towards the RCS floor was further supported by the shortest lying-down duration recorded on this type of floor. Bull cleanliness is an important hygienic and economic issue at slaughter, as extremely dirty animals could increase the risk of microbial contamination of carcass and meat (Lowe et al., 2001; Schulze Westerath et al., 2007). Research on flooring systems identified the drainage area and the floor material as the main factors affecting beef cattle cleanliness (Graunke et al., 2011). In our study, rubber covering reduced the drainage area of pens by $31 \%$, but only the cleanliness of $\mathrm{CH}$ bulls was impaired. Based on literature (Gygax et al., 2007b), we hypothesize that the increased faecal output as a consequence of the heavy BW was mainly responsible for the worsened cleanliness of these animals. Moreover, since a dirty and wet coat might cause bull discomfort increasing the risk of skin lesions (Bosilevac et al., 2005), the impaired cleanliness of $\mathrm{CH}$ bulls could explain the prevalence of integumental alterations recorded on RCS floor.

It has been reported that, regardless of the type of flooring system, the claw condition of fattening bulls becomes worse with an increase in bulls' BW (Stanek et al., 2004) and age (Fjeldaas et al., 2007). Moreover, the low abrasiveness of rubber flooring has shown to increase the occurrence of overgrown claws at the toe level resulting in longer dorsal wall and diagonal lengths compared to concrete flooring 
(Telezhenko et al., 2009). Our postmortem claw inspection clearly confirmed these findings suggesting further interesting outcomes. It is important to highlight that bull claws were never trimmed during fattening. Functional claw trimming is not a routine practice for beef cattle category due to the shortness of the fattening cycle and the high risk of injury for the trimmers. All bulls increased claws' length when kept in RCS pens; however, a significant sharpening of the toe angle was observed only in the claws of $\mathrm{CH}$ bulls. These animals completed their finishing at a higher BW than LIM bulls, and the sharpening of their toe angle might have been a way to bear a greater weight load over a longer period. This growth-wear unbalance of the claw horn would cause the shifting of the weight bearing point to the bulbs area (Toussaint Raven, 1985), predisposing the claws to develop specific disorders on the sole (Kremer et al., 2007). On the other hand, even a prolonged housing of $\mathrm{CH}$ bulls on concrete slatted floor is supposed to lead their claws to the development of sole and white line lesions, since abrasive and hard surfaces provoke an extreme wear of the claw horn (Telezhenko et al., 2008; Graunke et al., 2011).

\section{Conclusion}

On a perspective of the development of animal-friendly flooring systems tailor-made for specific beef cattle breeds, the use of RCS floor as an alternative to the CS floor could be advised for bulls like LIM that are finished at a lower final BW (around $600 \mathrm{~kg}$ ) than $\mathrm{CH}$ bulls. The problem of hoof overgrowth of these animals recorded on RCS floor might be prevented by introducing a certain percentage of a more abrasive surface in the floor pen. Results of this study show that, despite the positive growth performance, health and welfare of $\mathrm{CH}$ bulls finished at a final BW above $700 \mathrm{~kg}$ were impaired by their housing on both concrete or rubberized slatted floors. Therefore, alternative flooring systems to the fully slatted floor should be tested by future studies in order to improve health and welfare of these heavy animals.

\section{Acknowledgments}

The authors wish to thank all farmers for their availability to host the study, and AZOVE beef cattle Producers' Association and their veterinarians for the financial and technical support.

D L Magrin, 0000-0002-2153-6117

F Gottardo, 0000-0002-0427-2180

M Brscic, 0000-0001-8366-5961

B Contiero, 0000-0002-6586-5035

G Cozzi, 0000-0003-0408-1082

\section{Declaration of interest}

None.

\section{Ethics statement}

The animals of this study were handled according to ethical standards and valid regulations. The protocol of the study did not consider any procedure that would require a specific permission by an ethical board.

\section{Software and data repository resources}

None of the data were deposited in an official repository.

\section{References}

Absmanner E, Rouha-Mulleder C, Scharl T, Leisch F and Troxler J 2009. Effects of different housing systems on the behaviour of beef bulls - an on-farm assessment on Austrian farms. Applied Animal Behaviour Science 118, 12-19.

Alberti P, Panea B, Sanudo C, Olleta JL, Ripoll G, Ertbjerg P, Christensen M, Gigli S, Failla S, Concetti S, Hocquette JF, Jailler R, Rudel S, Renand G, Nute GR, Richardson $\mathrm{RI}$ and Williams JL 2008. Live weight, body size and carcass characteristics of young bulls of fifteen European breeds. Livestock Science 114, 19-30.

Association of Official Analytical Chemists (AOAC) 2000. Official Methods of Analysis, 17th edition. AOAC, Gaithersburg, MD, USA.

Bosilevac JM, Nou X, Osborn MS, Allen DM and Koohmaraie M 2005. Development and evaluation of an on-line hide decontamination procedure for use in a commercial beef processing plant. Journal of Food Protection 68, 265-277.

Brscic M, Gottardo F, Tessitore E, Guzzo L, Ricci R and Cozzi G 2015a. Assessment of welfare of finishing beef cattle kept on different types of floor after short- or long-term housing. Animal 9, 1053-1058.

Brscic M, Ricci R, Prevedello P, Lonardi C, De Nardi R, Contiero B, Gottardo F and Cozzi G 2015b. Synthetic rubber surface as an alternative to concrete to improve welfare and performance of finishing beef cattle reared on fully slatted flooring. Animal 9, 1386-1392.

Clarke AM, Drennan MJ, McGee M, Kenny DA and Berry DP 2009. Intake, live animal scores/measurements and carcass composition and value of late-maturing beef and dairy breeds. Livestock Science 126, 57-68.

Cozzi G 2007. Present situation and future challenges of beef cattle production in Italy and the role of the research. Italian Journal of Animal Science 6, 389-396.

Cozzi G, Tessitore E, Contiero B, Ricci R, Gottardo F and Brscic M 2013. Alternative solutions to the concrete fully-slatted floor for the housing of finishing beef cattle: effects on growth performance, health of the locomotor system and behaviour. Veterinary Journal 197, 211-215.

EFSA Panel on Animal Health and Welfare (AHAW) 2012. Scientific opinion on the welfare of cattle kept for beef production and the welfare in intensive calf farming systems. EFSA Journal 10, 2669, $166 \mathrm{pp}$.

Elmore MRP, Elischer MF, Claeys MC and Pajor EA 2015. The effects of different flooring types on the behaviour, health, and welfare of finishing beef steers. Journal of Animal Science 93, 1258-1266.

Fallon RJ and Lenehan JJ 2002. Factors affecting the cleanliness of cattle housed in buildings with concrete slatted floors. Beef Production Series, N 47. Teagasc, Grange Research Centre, Republic of Ireland.

Fjeldaas T, Nafstad O, Fredriksen B, Ringdal G and Sogstad AM 2007. Claw and limb disorders in 12 Norwegian beef-cow herds. Acta Veterinaria Scandinavica 49, 24.

Gallo L, De Marchi M and Bittante G 2014. A survey on feedlot performance of purebred and crossbred European young bulls and heifers managed under intensive conditions in Veneto, northeast Italy. Italian Journal of Animal Science 13, 798-807.

Graunke KL, Telezhenko E, Hessle A, Bergsten C and Loberg JM 2011. Does rubber flooring improve welfare and production in growing bulls in fully slatted floor pens? Animal Welfare 20, 173-183.

Gupta S, Earley B and Crowe MA 2007. Pituitary, adrenal, immune and performance responses of mature Holstein $\times$ Friesian bulls housed on slatted floors at various space allowances. Veterinary Journal 173, 594-604.

Gygax L, Mayer C, Schulze Westerath H, Friedli K and Wechsler B 2007a. On-farm assessment of the lying behaviour of finishing bulls kept in housing systems with different floor qualities. Animal Welfare 16, 205-208.

Gygax L, Siegwart R and Wechsler B 2007b. Effects of space allowance on the behaviour and cleanliness of finishing bulls kept in pens with fully slatted rubber coated flooring. Applied Animal Behaviour Science 107, 1-12. 


\section{Beef bulls on concrete or rubberized slatted floor}

Hocquette JF, Ellies-Oury MP, Lherm M, Pineau C, Deblitz C and Farmer L 2018 Current situation and future prospects for beef production in Europe - a review. Asian-Australasian Journal of Animal Sciences 31, 1017-1035.

Hoppe S, Brandt HR, König S, Erhardt G and Gauly M 2010. Temperament traits of beef calves measured under field conditions and their relationships to performance. Journal of Animal Science 88, 1982-1989.

Keane MP, McGee M, O'Riordan EG, Kelly AK and Earley B 2015. Effect of floo type on hoof lesions, dirt scores, immune response and production of beef bulls. Livestock Science 180, 220-225.

Kremer PV, Nueske S, Scholz AM and Foerster M 2007. Comparison of claw health and milk yield in dairy cows on elastic or concrete flooring. Journal of Dairy Science 90, 4603-4611.

Lowe DE, Steen RWJ and Beattie VE 2001. Preferences of housed finishing beef cattle for different floor types. Animal Welfare 10, 395-404.

Martin P and Bateson P 2007. Measuring behaviour. Cambridge University Press, Cambridge, UK.

Phillips CJC 1993. Cattle Behaviour. Farming Press Books, Ipswick, UK.

Phocas F, Boivin X, Sapa J, Trillat G, Boissy A and Le Neindre P 2006. Genetic correlations between temperament and breeding traits in Limousin heifers. Animal Science 82, 805-811.

Platz S, Ahrens F, Bahrs E, Nuske S and Erhard MH 2007. Association between floor type and behaviour, skin lesions, and claw dimensions in group-housed fattening bulls. Preventive Veterinary Medicine 80, 209-221.
Schulze Westerath H, Gygax L, Mayer C and Wechsler B 2007. Leg lesions and cleanliness of finishing bulls kept in housing systems with different lying area surfaces. Veterinary Journal 174, 77-85.

Stanek C, Frickh JJ and Karall P 2004. Claw condition and meat quality factors in fattening bulls in two different housing systems. In Proceedings of the 13th International Symposium and 5th Conference on Lameness in Ruminants, 11-15 February 2004; Maribor, Slovenija, pp. 193-195.

Telezhenko E, Bergsten C, Magnusson M and Nillson C 2009. Effect of different flooring systems on claw conformation of dairy cows. Journal of Dairy Science 92, 2625-2633.

Telezhenko E, Bergsten C, Magnusson M, Ventorp M and Nilsson C 2008. Effect of different flooring systems on weight and pressure distribution on claws of dairy cows. Journal of Dairy Science 91, 1874-1884.

Toussaint Raven E 1985. The principles of claw trimming. Veterinary Clinics of North America: Food Animal Practice 1, 93-107.

Van Soest PJ, Robertson JB and Lewis BA 1991. Method for dietary fiber, neutral detergent fiber and nonstarchpolysaccharides in relation to animal nutrition. Journal of Dairy Science 74, 3583-3597.

Wechsler B 2011. Floor quality and space allowance in intensive beef production: a review. Animal Welfare 20, 497-503.

Welfare Quality ${ }^{\circledR}$ 2009. Welfare Quality ${ }^{\circledR}$ Assessment Protocol for Cattle. Welfare Quality ${ }^{\circledR}$ Consortium, Lelystad, The Netherlands. 